\title{
Turkish Primary Teacher Candidates' Conceptual Understandings of Gases
}

\author{
Fatma Aggul Yalcin, Mehmet Yalcin* \\ Department of Mathematics and Science Education, Faculty of Education, Agri Ibrahim Cecen University, Agri, Turkey
}

*Corresponding Author: myalcin@agri.edu.tr

\section{ABSTRACT}

The purpose of this study was to determine Turkish primary teacher candidates' conceptual understandings of gases. In this study, a survey approach was used. The sample consisted of 240 primary teacher candidates. As the data collection tool, a questionnaire of six questions consisting of three open-ended and three multiple choice was used. The validity and reliability of the questionnaire were provided using the opinions of three field experts and the reliability analysis for multiple-choice ones. The responses to the open-ended questions and the drawings were analyzed descriptively using the predetermined codes and then the categories were formed. The findings showed that primary teacher candidates had some common misunderstandings of gases and their level of understanding of gases is rather low. It is suggested that more attention should be given to developing a correct understanding of the fundamental science concepts in primary teacher training.

KEY WORDS: science teacher training; teaching gases; chemistry misconceptions

\section{INTRODUCTION}

$\mathbf{P}$ revious research of students' understanding and reasoning about various science subjects and concepts shows that students' existing concepts are quite different from those generally accepted in science and students develop some informal ideas to explain scientific issues (Driver and Easly, 1978; Stavy, 1991; Ozmen, 2004). In addition, students develop their own ideas about basic concepts before starting science classes and these often differ from the accepted scientific knowledge (Driver et al., 1994).

Students' understanding of the natural world can facilitate or prevent them from learning new scientific concepts (Hewson, 1982). The existing concepts of students are constructed by the interaction between their cognitive systems and their physical, social, and cultural environments (Stavy, 1991). In studies, it has been determined that students' achievements in problems requiring conceptual knowledge are insufficient (Kautz et al., 2005; Hammar, 2013). This situation arises from both the students' inability to develop a correct conceptual understanding and their misconceptions. It is of great importance that the concepts that begin to form from birth develop with the interaction with the environment. In addition, we need to ensure that they develop an understanding and explanation of their world correctly because a correct conceptual understanding enables the individual to understand events, explain their knowledge, transfer their knowledge to new, different situations, transform them into new information forms, interpret them, and think analytically.
Structures different from those scientifically accepted have been called by different names such as misconceptions, preconceptions, alternative structures, science of children, and insufficient understandings (Novak, 1977; Driver and Easley, 1978; Gilbert et al., 1982; Fisher, 1985; Lin et al., 2000; Griffiths and Grant, 1985; Palmer, 2001; Southerland et al., 2001). There exists a variety of misconceptions in chemistry as this is one of the subjects that many students have difficulty in learning (Demircioglu et al., 2005).

Chemistry contains abstract concepts that play an important role in the advanced learning of different fields of science. To learn these concepts incorrectly, negatively affects advanced learning. This situation in addition to the use of some chemistry concepts with different meanings in daily life leads to difficulties in understanding the subject (Taber, 2002a; Yalcinkaya, 2010). Thus, the identification of students' misconceptions has great importance to improve teaching and learning chemistry (Garnett et al., 1995). Due to the difficulties encountered in linking gas concepts with daily life, gases are one of the chemistry concepts in which students have both misconceptions and difficulty developing a conceptual understanding at the molecular level (Azizoglu and Geban, 2004; Doymus, 2007; Koc, 2014; Sahin and Cepni, 2012).

Gas concepts require a conceptual understanding of the particle structure of matter, the states of matter, and phase changes (Seda Cetin, 2009). At the same time, it is the basis for topics such as chemical reactions, chemical equilibrium, and solutions. Therefore, developing a correct conceptual understanding of gases is important in terms of learning 
chemistry. It has been determined that not only students but also teachers can have an inadequate conceptual understanding of gases (Bak Kibar et al., 2013). Similarly, teachers' incomplete conceptual understanding has an impact on students' insufficient understanding or misconceptions (Westbrook and Marek, 1992). A study by Azizoglu and Geban (2004) of the $10^{\text {th }}$ grade students' preconceptions and misconceptions of gases found students' misconceptions persisted after the teaching of gases.

\section{Student-teacher Misconceptions}

A study was conducted to determine primary student-teachers' understanding level of the temperature-volume-pressure relationship in gases and the extent to which they could associate the situations encountered in the daily life with this subject. Birinci Konur and Ayas (2010) observed that student-teachers learned the concept of gas well, but they had difficulty understanding the relationship between temperaturepressure-volume in gases and had insufficient understanding or misunderstandings in the concepts related to factors influencing gas properties. Likewise, Kariper (2013) explored pre-service science teacher candidates' misconceptions and misunderstandings about gases. Kariper (2013) noted some misconceptions appeared mainly in studies of younger age groups and they had inadequate learning about gases. Koc (2014) aimed to determine science students' level of understanding of the subject of gases at the microdimension. The findings showed that students have misconceptions such as associating the distribution of gases with their molecular masses and not recognizing that gases fill the volume of the container. Finally, Pathare and Pradhan (2010) found that undergraduate physics students believed that a gas has no mass and some of them thought negligible mass means no mass. The other misconceptions identified were, "If the gas is in a closed container it has mass, but if it is in an open container it has no mass," "the molecules of an ideal gas exert no interactive forces whatsoever, as a result, they do not exert any pressure on the walls of the container," and "the change in volume from the liquid state to the vapor state is due to change in the size of molecules or breaking of molecules" (Pathare and Pradhan, 2010).

\section{Misconceptions about Gases}

Lin et al. (2000) studied high school students' and chemistry teachers' understanding of gas laws. Their results showed that although students remembered the formula of $\mathrm{PV}=\mathrm{nRT}$, they misused it, could not give meaningful explanations to questions, and they had misconceptions. It was determined that the majority of the students could not illustrate the gas inside a bottle correctly and that the movement of the gas molecules at different temperatures explained by taking into account human-specific vitality. It has also been found that they had misconceptions, such as that the atmospheric pressure pushes the gas molecules to keep them at the bottom of the bottle, when heated the gas molecules are elevated and away from the heat, and when the temperature increases, the gas molecules have expanded.
Hwang (1995), in his study on Taiwan secondary and high school students' understandings of the concept of gas volume, found the misconceptions that the volume of a gas is a particle size, there is no volume of gases and they are freely dispersible, and the volumes of different gases are proportional to the number of particles in the container. Besides, it was determined that their misconceptions decreased as the grade increased.

In the study conducted by Calik and Ayas (2005), they attempted to determine the conceptions of the $8^{\text {th }}$ grade students and pre-service teachers about the concept of gas and it was found that they had similar alternative concepts with students even though having more chemistry education. It was found that the misconceptions such as the gases had a constant volume but did not contain a constant mass, and the intermolecular bond was the longest in the gas phase. It is suggested that the similar misconceptions in both student and teacher candidates are related to misuses of the concepts in daily life.

Erceg et al. (2016) studied university students' understandings of the ideal gas law and its application in solving problems. Some misconceptions determined by them are the following:

Gas particles with less kinetic energy move slower and, consequently, occupy a smaller volume.

Molecules of greater mass generate higher pressure on a given temperature.

The intermolecular collisions generate temperature, heat, or kinetic energy of molecules. Therefore, temperature, heat, or kinetic energy of the molecules increase with the increase in the frequency of intermolecular collisions, either because of a decrease of the vessel's volume or because of an increase of the number of molecules.

Erceg et al. (2016) advocated that most of the misconceptions were due to an inadequate microscopic picture of the gas. Moreover, they suggested that the natural way of introducing the kinetic model of matter in the elementary school was to use the analogy with moving balls. As for the university students, the simplest consistent mechanical model of gas should be a model that includes no central elastic collision between the balls of finite sizes, such as dispersing billiards.

There are also problems due to the idealization of gases. In the case of real gases, sometimes, the ideal gas approach was used by students. Leinonen et al. (2012) reported that the ideal gas law is a very attractive model for students to apply to various situations where it is not necessarily valid. They emphasized that students think all tasks or problems related to gases can be solved with the ideal gas law, even though the law is often inappropriate.

There are many studies about the conceptual understandings and misconceptions of gases and the use of various methods to overcome these (Niaz, 2000; Azizoglu and Geban, 2004; Seda Cetin, 2009; Yalcinkaya, 2010; Birinci Konur and Ayas, 2010; 
Aydeniz et al., 2012; Bak Kibar et al., 2013; Yavuz and Celik, 2014). However, in considering the place of the gas subject in the chemistry curriculum and the issues related to it, it is clear that developing a scientifically valid conceptual understanding and the validity of primary school teachers' conceptual structure of gases have great importance. In the primary education period, where the first scientific concepts form, teachers' conceptions make a foundation for individuals' later educational achievements. However, in the research literature, the number of studies aimed at determining the understanding of primary teachers or primary teacher candidates directly on gases is limited (Birinci Konur and Ayas, 2010). Hence, this study aimed to determine the conceptual understanding of the pre-service teachers about the gases.

\section{METHODOLOGY}

In this study, the survey approach was used. Surveys can be used to describe attitudes, beliefs, opinions, and other types of information (Mcmillan and Schumacher, 2001).

\section{Sample}

This study used the convenience sampling approach, in which the study group was selected on the basis of being accessible. Although this type of sample makes it easier to conduct the study, the findings may not be generalized to the wider population (Mcmillan and Schumacher, 2001). The sample consisted of 240 primary teacher candidates (aged between 19 and 25 years old) enrolled in a faculty of education in a state university. The participants were from the middle and lower socioeconomic levels (80\% middle status and 20\% lower status), of which 132 were female and 108 male. Before the study, the participants were informed that their participation in the research was voluntary and that they could withdraw from it at any time. They took a weekly $2 \mathrm{~h}$ general chemistry course over a 14-week semester of which 4 weeks of the course focused on gases. The traditional teacher-centered teaching approach was used in the courses.

\section{Data Collection Tool}

In the study, a questionnaire of a total of six questions with three open-ended and three multiple-choice questions developed by the researchers considering previous studies (Koc, 2014; Seda Cetin, 2009; Petrucci et al., 2002) was used. To determine the reliability of the questionnaire, it was piloted on a similar group and the reliability coefficient was calculated to be 0.81 . The validity of the questionnaire was provided using the opinions of three field experts.

\section{Data Analysis}

The collected data were descriptively analyzed and all questions in the scale were analyzed separately. The responses to the open-ended questions and the drawings were analyzed using the codes predetermined from the questions and then the categories were formed (Mcmillan and Schumacher, 2001). The analysis of qualitative data was conducted by two researchers and their findings showed compatibility of $81 \%$.

\section{RESULTS AND DISCUSSION}

In this section, the findings with frequency and percentage values from the analysis of each question are tabled separately and then discussed in detail. As shown in Table 1, 60\% of the pre-service teachers answered correctly that the pressure of the ideal gas increases with the increase of temperature in a closed container. However, it was found that those who gave this response only answered algorithmically the question by considering the positive correlation between pressure and temperature in the ideal gas equation and did not provide a conceptual explanation at the molecular level.

On the other hand, $31 \%$ of them had the misconception that with the temperature increase the pressure of the ideal gas in the closed container decreased. However, they could not provide an accurate explanation at the molecular level.

From Table 2, it is understood that while a significant part of the prospective teachers (31\%) offered a correct conceptual explanation that "when increased the temperature of oxygen and helium gas mixture in a closed container, the speed of the particles increased but the distribution of the mixture did not change," $10 \%$ of them claimed oxygen with a larger molecular weight gathered at a place closer to the upper part of the vessel. This misconception may be related to the observation of a macroscopic change occurring in some heating processes, such as heating the milk. A study conducted by Ayyildiz and Tarhan (2013) determined that students had an improper conceptual understanding such as "gas molecules heated in the closed container are collected in the upper part of the vessel," and "by the increase of energies of gas molecules heated in the closed container they are to be get heavy and be located in the lower part of the container." This demonstrated that students had the perception that the gases were not uniformly distributed in the container. A similar misconception that "gas has a regular structure" was in studies by both Gabel et al. (1987) and Ozmen (2011).

Robertson and Shaffer (2013) stated students think that the volume of the gas decreases when cooled by arguing that less energetic particles take up less space. They pointed out students' reasoning could be divided into two subcategories. The first was that the slower motion of the gas particles implied less movement or "activity," and thus, the particles occupied less space. A second reason for this situation was that lower

\begin{tabular}{|c|c|c|}
\hline Opinions & $f$ & $\%$ \\
\hline $\begin{array}{l}\text { If the temperature of an ideal gas in the closed container } \\
\text { increases, the pressure decreases as the temperature is } \\
\text { inversely proportional to the pressure }\end{array}$ & 81 & 31 \\
\hline $\begin{array}{l}\text { If the temperature of an ideal gas in the closed container } \\
\text { increases, the pressure increases because the pressure and the } \\
\text { temperature are directly proportional }\end{array}$ & 159 & 60 \\
\hline
\end{tabular}




\begin{tabular}{|c|c|c|}
\hline Opinions & $f$ & $\%$ \\
\hline \multicolumn{3}{|l|}{$\begin{array}{l}\text { When the temperature of the non-reacting ideal gas } \\
\text { mixture in the closed container is increased }\end{array}$} \\
\hline $\begin{array}{l}\text { The speed of particles increases but the distribution does } \\
\text { not change }\end{array}$ & 81 & 31 \\
\hline $\begin{array}{l}\text { As the temperature increases, the particles get closer to } \\
\text { each other }\end{array}$ & 24 & 10 \\
\hline $\begin{array}{l}\text { Gas with larger molecular weight is located in the upper } \\
\text { part of the container }\end{array}$ & 24 & 10 \\
\hline $\begin{array}{l}\text { Gas with a small molecular weight is located to the upper } \\
\text { part of the container }\end{array}$ & 6 & 2 \\
\hline \multicolumn{3}{|l|}{$\begin{array}{l}\text { When the closed container including a gas mixture is } \\
\text { inverted at the same temperature and pressure }\end{array}$} \\
\hline Distribution of gas mixture does not change & 81 & 31 \\
\hline $\begin{array}{l}\text { While gas with larger molecular weight remains at the } \\
\text { bottom of the container, one with low molecular weight } \\
\text { is located to upper }\end{array}$ & 90 & 34 \\
\hline $\begin{array}{l}\text { While molecules at the bottom are located to the upper } \\
\text { part of the container and the ones at upper are located at } \\
\text { the bottom }\end{array}$ & 33 & 13 \\
\hline \multicolumn{3}{|l|}{$\begin{array}{l}\text { When the closed container including a gas mixture is laid } \\
\text { on the side at the same temperature and pressure }\end{array}$} \\
\hline Distribution of gas mixture does not change & 69 & 26 \\
\hline $\begin{array}{l}\text { While gas with a larger molecular weight remains at the } \\
\text { bottom of the container, one with low molecular weight } \\
\text { moves to upper }\end{array}$ & 84 & 32 \\
\hline $\begin{array}{l}\text { Since gas is squeezed to a narrower volume, the space } \\
\text { between the gas particles decreases }\end{array}$ & 45 & 17 \\
\hline
\end{tabular}

energy particles cannot "keep themselves up" in the container. Robertson and Shaffer (2013) noted that concerning the variation in the distribution of particles on cooling of the gas, their participating students considered the effect of gravity on the slower moving particles. They highlighted students treated gravity as having a significant impact on the particles at the lower temperature. In addition, those students held that gases condensed or contracted when cooled, regardless of the conditions. Rather than treating a phase change as occurring at a particular temperature, they treated the transition from gas to liquid as taking place over a range of temperatures. Interchangeable use of the volume of the gas and the number of particles of the gas were another misconception encountered. The authors concluded that many students did not connect a correct microscopic model for gases to the macroscopic concept of volume. In some cases, they correctly used the basic tenets of kinetic molecular theory in some contexts but did not apply them in others.

Pathare and Pradhan (2010) studied student drawings of air in a container at different pressures and temperatures. Their results showed that for air at a temperature of $30^{\circ} \mathrm{C}$ and pressure of one atmosphere, the students showed the air molecules in the container properly spatially arranged. When the pressure was reduced, the students drew far fewer molecules in a substantially larger part of the container below the mouth of the container. For air at a temperature of $90^{\circ} \mathrm{C}$ and a pressure of one atmosphere, they stated since the temperature increased to $90^{\circ} \mathrm{C}$, the walls of the container become hot; the air became much less dense. As a result, there was crowding in the center of the container. Some of them thought that since the temperature was increased, the air became lighter and hence it rose to concentrate at the top of the container.

As shown from Table 2, to the question of inverting the gas container, a significant part (31\%) of the pre-service teachers responded that the distribution of the gas mixture did not change, while $34 \%$ of them thought the distribution changed and placed oxygen with a higher molecular weight at the bottom and helium with a lower molecular weight near the top. A similar finding was reported by Koc (2014). This misunderstanding could be the result of everyday observations such as the separation of muddy water into distinct layers. It is apparent from the above table that $13 \%$ developed the unacceptable conceptual understanding that the molecules initially at the bottom rose and the ones on the top came down, that is, to say, the two gases exchanged places. Here, it could be inferred that these prospective teachers imagined the gas mixture was like a mechanically rotatable solid rather than a dynamical microscopic system.

Of the prospective teachers $(32 \%)$, in the case, where the container involving a gas mixture was tilted, had the understanding that the oxygen with a higher molecular weight was lower down in the container; the helium with a lower molecular weight rose to the top; and the mixture was squeezed into a narrow space and thus the gap between the particles decreased. It is clearly an invalid conceptual understanding. The candidates did not consider that when the orientation of the container changed, the gases spread homogeneously throughout the entire container and they assumed that the container expanded and occupied a volume corresponding to a certain height beginning from the bottom of the container. Therefore, they incorrectly applied the situation that is valid for liquids to gases. This was similar to Koc's (2014) findings. That study reported that the students equated gas distribution to the density of gas and that the gas with larger molecular mass was located near the lower portion of the vessel and its density became higher. In addition, in the studies by Lee et al. (1993) and Lin et al. (2000) about a gas mixture in the closed container, they found the misunderstanding that a gas with lower molecular weight collected in the upper portion of the container. These authors highlighted that the particulate nature of the substance was only learned conceptually.

As indicated in Table 3, the majority of the prospective teachers $(60 \%)$ gave a correct response, but a non-molecular explanation that the pressure of the gas mixture reduced if the container volume was doubled. About $14 \%$ of them stated that the pressure of the gas mixture increased. It is clear from the table that students thought the same gases created more pressure when in a larger volume. This implies how important 


\begin{tabular}{|c|c|c|}
\hline Opinions & $f$ & $\%$ \\
\hline $\begin{array}{l}\text { When the gas mixture in a closed container at a constant } \\
\text { temperature is transferred to a larger volume, the pressure of } \\
\text { the gas mixture decreases as the volume increases }\end{array}$ & 159 & 60 \\
\hline $\begin{array}{l}\text { When the gas mixture in a closed container at a constant } \\
\text { temperature is transferred to a larger volume, the particles } \\
\text { exert more pressure in a larger volume }\end{array}$ & 36 & 14 \\
\hline $\begin{array}{l}\text { When the temperature of the container is reduced, the } \\
\text { pressure decreases as the temperature and gas pressure are } \\
\text { proportional }\end{array}$ & 126 & 48 \\
\hline
\end{tabular}

it is to grasp gas phenomena at the molecular level. It could be inferred from this that since pre-service teachers did not know the concept of gas pressure at the molecular level. The study by Seda Cetin (2009) reported that students connected the gas pressure with the shape of the container. A similar misunderstanding was found in the study conducted by Aydeniz et al. (2012) in that an increase in the gas volume in a closed system caused an increase in pressure and temperature. This study's teacher candidates (48\%) responded correctly that as the temperature of the gas mixture was lowered its pressure would decrease and they stated that there was a direct positive proportionality between the temperature and pressure. It meant that they tried to solve the question algorithmically. On the other hand, in the study by Kind (2004), it was noted the misconception that the reduction in the volume of the cooled gas was not associated with a decrease in the motion of particles, but due to gravitational forces between the particles.

From Table 4, it is understood that while the pre-service teachers (63\%) responded correctly in the way that the temperature increases of gas resulted in an increase in its volume, $31 \%$ of them claimed to decrease its volume. Moreover, the majority $(70 \%)$ believed gas pressure increased. It was found that they thought the gas concentration increased (53\%) with increasing temperature and the concentration of gas was unchanged (13\%). Just $25 \%$ held the correct answer "gas concentration is reduced." Almost half of them (53\%) gave the response "the average kinetic energy of the gas molecules increase with increasing temperature" which is an acceptable one.

In the previous studies about the behavior of gases with increasing temperature, misconceptions include when a piston container is heated, the temperature and PV product value decrease inversely (Seda Cetin, 2009); if the temperature increases, kinetic energy decreases (Yavuz and Celik, 2014); gas molecules expand with increasing temperature (Lin et al., 2000; Aydeniz et al., 2012; Seda Cetin, 2009); gas molecules are collected in the upper part of the container (Seda Cetin, 2009; Ayyildiz and Tarhan, 2013); and both pressure and volume increase (Seda Cetin, 2009). De Berg (1995) reported students' understanding of the pressure of enclosed air was context specific, that is, the enclosed air exerts pressure when

\begin{tabular}{|c|c|c|}
\hline Views & f & $\%$ \\
\hline The volume of gas increases with increasing temperature & 165 & 63 \\
\hline The volume of a gas decreases with increasing temperature & 81 & 31 \\
\hline The pressure of a gas increases with increasing temperature & 186 & 70 \\
\hline The pressure of a gas decreases with increasing temperature & 33 & 13 \\
\hline $\begin{array}{l}\text { The pressure of gas remains constant with increasing } \\
\text { temperature }\end{array}$ & 15 & 6 \\
\hline Gas concentration increases with increasing temperature & 141 & 53 \\
\hline Gas concentration decreases with increasing temperature & 66 & 25 \\
\hline $\begin{array}{l}\text { Gas concentration remains constant with increasing } \\
\text { temperature }\end{array}$ & 33 & 13 \\
\hline $\begin{array}{l}\text { Average kinetic energies of gas molecules increase with } \\
\text { increasing temperature }\end{array}$ & 141 & 53 \\
\hline $\begin{array}{l}\text { Average kinetic energies of gas molecules remain constant } \\
\text { with increasing temperature }\end{array}$ & 63 & 24 \\
\hline $\begin{array}{l}\text { Kinetic energies of gas molecules decrease with increasing } \\
\text { temperature }\end{array}$ & 33 & 13 \\
\hline
\end{tabular}

pushed, but no pressure when not pushed. It seems that the student-teachers did not have the idea that the temperature increased in the piston container in mechanical equilibrium with its surrounding would cause an increase in pressure and so remove mechanical equilibrium; it would cause the expansion of container until again internal and external pressures were equal.

When Table 5 is examined, it can be seen that $48 \%$ of the prospective teachers had the misconception that when the gas volume was reduced the molecules would squeeze and shrink their molecular size. Only $43 \%$ held a correct conceptual understanding and gave the response that through the reduction of the volume, the number of molecules hitting on a unit surface per unit time increased. The misconception found in the current study bears similarity to the understandings "the size of gas molecules decreases with the reduction in volume" (Seda Cetin, 2009) and "volume of a gas is the size of its particles" (Hwang, 1995). It appears that students did not explain the results of the volumetric decrease in the gases with the lowering interparticle distance as a result of coming particles together, but they tried to explain it with a new variable, the size of particles with shrinkable and expandable features. A study by Ozmen (2011) found students thought that particle size and the number of particles would increase during heating and decrease during cooling. Ozmen interpreted this situation in the way that students did not make the distinction between macroscopic and microscopic properties of matter and attributed the observable changes to microscopic phenomena.

The misconception that "Pressure affects the shape of molecules" reported by Nakhleh (1992) is thought to be related to this kind of reasoning encountered in the prospective teachers in the present study. Such a conceptual understanding could be stem from illustrating the particles as "spheres" in 
teaching the granular structure of the matter. This approach could have led the students to develop the idea that matter is composed of solid beads and may undergo shape change with pressure (Karakoc Topal, 2018). Thus, it bears great importance for teachers to emphasize that the form of the particles forming matter is not changed with increasing pressure but just the distance between the particles.

As can be shown in Table 6, 44\% of pre-service teachers stated that there was "air" between molecules in a gas. While $28 \%$ claimed that there were foreign substances, others believed the existence of water vapor $(15 \%)$ or other gases (13\%); just $23 \%$ of them put forward the idea that there was nothing between them. Studies conducted by Novick and Nussbaum (1978; 1981), Lee et al. (1993), and Azizoglu and Geban (2004) explored misconceptions such as: Among gas particles, there may exist air, dirt, microbes, liquid, or unknown vapors. It was suggested that the students had limited experience with the concept of a vacuum in their daily lives, that is, they see air, water, or various solids that fill the space at the macroscopic level and so they tend to explain gaseous phenomena using previous macroscopic experiences. Karakoc Topal (2018) pointed out students' weak conceptual understanding of the space between gas particles as the reason for this misunderstanding.

The findings of this study showed that primary teacher candidates had a weak conceptual understanding and various alternative concepts in terms of gases. It was found that the candidates who answered the questions correctly were found to offer inadequate conceptual explanations and generally only reached the correct answers algorithmically. According to Suits (2000), there are two types of understanding of chemistry: The

\section{Table 5: Prospective teachers' opinions of the results of decreasing the volume of an ideal gas in a closed piston at a constant temperature

\begin{tabular}{lcc}
\hline Opinions & $\mathbf{f}$ & $\%$ \\
\hline $\begin{array}{l}\text { When the volume of an ideal gas in a closed piston at } \\
\text { constant temperature is decreased, the gas pressure increases } \\
\text { since the number of molecules hitting on a unit surface per }\end{array}$ & 102 & 43 \\
unit time increases & \\
When the volume of an ideal gas in a closed piston at & 114 & 48 \\
constant temperature is decreased, the size of the molecule & \\
is reduced with lowering the volume, because the reducing \\
volume was to cause the molecules to shrink
\end{tabular}

Table 6: Teachers candidates' opinions about interatomic/ intermolecular space in gases

\begin{tabular}{lcc}
\hline Opinions & $\mathbf{f}$ & $\%$ \\
\hline There is air among atoms/molecules in a gas & 105 & 44 \\
There is water vapor among atoms/molecules in a gas & 36 & 15 \\
There are other gases among atoms/molecules in a gas & 30 & 13 \\
There is nothing among the atoms/molecules in a gas & 54 & 23 \\
There are foreign substances (dust, dirt, etc.) among atoms/ & 66 & 28 \\
molecules in a gas & &
\end{tabular}

algorithmic understanding and conceptual understanding. It has been reported that to pass examinations, students frequently only need to use mathematical procedures, and learning by rote instead of learning conceptual theories about gases (Fellows, 1994).

A large number of students can solve the problems they face numerically without learning the concepts. While students are proficient in solving symbolic problems not related to real-world problems, they seem to be insufficient in using, explaining, and relating the concepts. This can be the result of the fact that the students are presented chemistry knowledge by the chemistry teachers and course books, which leads to symbolic comprehension rather than contextual content, and ignores the nature and content of gas laws. It is usually accepted that students come to the class with a correct conceptual understanding of the real world. However, this is not always true. In fact, their understandings often facilitate or prevent them from learning new scientific concepts (Hewson, 1982). Chemistry, which is an important science in providing students an understanding of what is going on around them, contains many abstract concepts (Taber, 2002a). The subject of gases is a difficult one to learn for the students who have the principle "Seeing is believing." So, the misconceptions such as "gases are invisible and massless" are the significant obstacles for them to overcome. Besides, the degree of immediate observability of referents corresponding to the concepts is effective in its degree of abstraction. Therefore, the more a concept is experienced, the more conceptual structure is formed and gotten complex. Again, the intense mathematical structure of the subject of gases directed students to memorize relationships and algorithmic thinking instead of developing a conceptual understanding (Taber, 2002b; Stavy, 1988).

\section{CONCLUSION}

The results of this study gain even more importance considering teachers' incomplete understanding and alternative concepts (Westbrook and Marek, 1992), which is one of the reasons why students lack insufficient conceptual understanding of gases. In particular, the development of science concepts of children is directly related to classroom instruction. Taking into consideration the fact that teacher candidates may be offering education with an insufficient conceptual understanding and misconceptions are it any wonder that many children develop a scientifically inappropriate conceptual structure about the gases.

A proper understanding of the gases that have an important place in the daily life of students makes learning easier and makes connections between the previous concepts and the new ones. As reported in the previous studies (Azizoglu and Geban, 2004; Calik and Ayas, 2005; Demircioglu and Ercebi, 2013; Erten and Yildirim, 2010; Koc, 2014), many students have an inappropriate conceptual understanding of the properties of gases. It has been noted that these misconceptions develop in the early years of school (Benson et al., 1993) and they are 
resistant to transformation into scientifically accepted concepts (Azizoglu and Geban, 2004). Therefore, the importance of primary teacher training is clear.

From the findings of the present study, it is clear that the preservice teachers hold some misunderstandings reported also in the literature about the gases and they developed false or inadequate conceptual understanding. Keeping in the mind the fact that pre-service teachers are to address students at primary level, more attention should be given to developing a correct understanding of the fundamental science subjects like gases. Therefore, the findings of this study are thought to be valuable for researchers and teacher educators.

\section{REFERENCES}

Aydeniz, M., Pabuccu, A., Cetin, P.S., \& Kaya, E. (2012). Argumentation and students' conceptual understanding of properties and behaviors of gases. International Journal of Science and Mathematics Education, 10, 1303-1324.

Ayyildiz, Y., \& Tarhan, L. (2013). Case study applications in chemistry lesson: Gases, liquids, and solids. Chemistry Education Research and Practice, 14, 408-420.

Azizoglu, N., \& Geban, Ö. (2004). Students' preconceptions and misconceptions about gases. Balikesir University Journal of Graduate School, 6(1), 73-78.

Bak Kibar, Z., Yaman, F.F., \& Ayas, A. (2013). Assessing prospective chemistry teachers' understanding of gases through qualitative and quantitative analyses of their concept maps. Chemical Education Research and Practice, 14, 542-554.

Benson, D.L., Wittrock, M.C., \& Baur, M.E. (1993). Students'preconceptions of the nature of gases. Journal of Research in Science Teaching, 30(6), 587-597.

Birinci Konur, K., \& Ayas, A. (2010). Primary school teachers' understanding level of temperature-volume-pressure relationship in gases. Journal of Turkish Science Education, 7(3), 128-142.

Calik, M., \& Ayas, A. (2005). A comparison of level of understanding of eighth-grade students and science student teachers related to selected chemistry concepts. Research in Science Teaching, 42(6), 638-667.

De Berg, K.C. (1995). Student understanding of the volume, mass, and pressure of air within a sealed syringe in different states of compression. Journal of Research in Science Teaching, 32(8), 871-884.

Demircioglu, G., \& Ercebi, M. (2013). Comparison of science teacher candidates' performances in conceptual and algorithmic chemistry questions. Amasya University Journal of Education Faculty, 2(1), 145-169.

Demircioglu, G., Ayas, A., \& Demircioglu, H. (2005). Conceptual change achieved through a new teaching program on acids and bases. Chemistry Education Research and Practice, 6(1), 36-51.

Doymus, K. (2007). The effect of a cooperative learning strategy in the teaching of phase and one-component phase diagrams. Journal of Chemical Education, 84(11), 1857-1860.

Driver, R., \& Easley, J. (1978). Pupils and paradigms: A review of literature related to concept development in adolescent science students. Studies in Science Education, 5, 61-84.

Driver, R., Squires, A., Rushworth, P., \& Wood-Robinson, V. (1994). Making Sense of Secondary Science: Research into Children's Ideas. Abingdon, United Kingdom: Routledge.

Erceg, N., Aviani, I., Mešić, V., Glunčić, M., \& Žauhar, G. (2016). Development of the kinetic molecular theory of gases concept inventory: Preliminary results on university students' misconceptions. Physical Review Physics Education Research, 12, 020139.

Erten, H., \& Yıldırım, B. (2010). The Determination of Primary Teacher Candidates' Conceptions, Understanding Levels and Misconceptions of Gases. Elazig, Turkey: Paper Presented at $9^{\text {th }}$ National Primary teacher training Symposium.

Fellows, N.J. (1994). A window in to thinking: Using student writing to understand conceptual change in science learning. Journal of Research in Science Teaching, 31(9), 985-1001.

Fisher, K. (1985). A misconception in biology: Amino acids and translation. Journal of Research in Science Teaching, 22, 53-62.

Gabel, D.L., Samuel, K.V., \& Hunn, D. (1987). Understanding the particulate nature of matter. Journal of Chemical Education, 64(8), 695-697.

Garnett, P.J., Garnett, P.J., \& Hackling, M.W. (1995). Students 'alternative conceptions in chemistry: A review of research and implications for teaching and learning. Studies in Science Education, 25, 69-95.

Gilbert, J.K., Watts, D.M., \& Osborne, R.J. (1982). Students' conceptions of ideas in mechanics. Physics Education, 17, 62-66.

Griffiths, A.K., \& Grant, B.A.C. (1985). High school students' understanding of food webs: Identification of a learning hierarchy and related misconceptions. Journal of Research in Science Teaching, 22, 421-436.

Hammar, M. (2013). Teaching the Gas Properties and Gas Laws: An Inquiry Unit with Alternative Assessment. Master's Thesis, Michigan Technological University. Available from: http://www.digitalcommons. mtu.edu/etds/ 698 .

Hewson, P.W. (1982). A case study of conceptual change in special relativity: The influence of prior knowledge in learning. European Journal of Science Education, 4, 61-78.

Hwang, B.T. (1995), Student's Conceptual Representations of Gas Volume in Relation to Particulate Model of Matter. San Francisco: Annual Meeting of the National Association for Research in Science Teaching.

Karakoc Topal, O. (2018). Matter, states of matter and state changes. In: Dolu, G., (Ed.), Misconceptions in Chemistry. $1^{\text {st }}$ ed. Turkey, Ankara: Pegem Academy. pp. 5-6.

Kariper, I.A. (2013). Primary science teacher candidates' misconceptions on gases. Journal of European Education, 3(1), 33-35.

Kautz, C.H., Heron, P.R.L., Loverude, M.E., \& McDermott, L.C. (2005). Student understanding of the ideal gas law, part I: A macroscopic perspective. American Journal of Physics, 73(11), 1055-1063.

Kind, V. (2004). Beyond Appearances: Students' Misconceptions about Basic Chemical Ideas. $2^{\text {nd }}$ ed. United Kingdom: Royal Society of Chemistry.

Koc, Y. (2014). Science students' understanding level of gases topic at micro level. E-Kafkas Journal of Educational Research, 1(1), 40-48.

Lee, O., Eichinger, D.C., Anderson, C.W., \& Berkheimer, G.D. (1993). Changing middle school students' conceptions of matter and molecules. Journal of Research in Science Teaching, 30, 249-270.

Leinonen, R., Asikainen, M.A., \& Hirvonen, P.E. (2012). University students explaining adiabatic compression of an ideal gas-a new phenomenon in introductory thermal physics. Research in Science Education, 42, 11651182.

Lin, H., Cheng, H., \& Lawrenz, F. (2000). The assessment of students and teachers' understanding of gas laws. Journal of Chemical Education, 77(2), 235-238.

Mcmillan, J.H., \& Schumacher, S. (2001). Research in Education. $5^{\text {th }}$ ed. Harlow: Longman.

Nakhleh, M.B. (1992). Why some students don't learn chemistry. Journal of Chemical Education, 69(3), 191-195.

Niaz, M. (2000). Gases as idealized lattices: A rational reconstruction of students' understanding of the behavior of gases. Science Education, 9, 279-287.

Novak, J.D. (1977). A Theory of Education. Ithaca, New York: Cornell University Press.

Novick, S. \& Nussbaum, J. (1981). Pupils' understanding of the particulate natüre of matter: Across age study. Science Education, 65(2), 187-196.

Novick, S., \& Nussbaum, J. (1978). Junior high school pupils' understanding of the particulate nature of the matter: An interview study. Science Education, 62(3), 273-281.

Ozmen, H. (2004). Some student misconceptions in chemistry: A literature review of chemical bonding. Journal of Science Education and Technology, 13(2), 147-159.

Ozmen, H. (2011). Turkish primary students' conceptions about the particulate nature of matter. International Journal of Environmental and Science Education, 6(1), 99-121.

Palmer, D. (2001). Students' alternative conceptions and scientifically acceptable conceptions about gravity. International Journal of Science Education, 23(7), 691-706.

Pathare, S.R., \& Pradhan, H.C. (2010). Students' misconceptions about heat transfer mechanisms and elementary kinetic theory. Physics Education, 
45(6), 629-634

Petrucci, R.H., Harwood, W.S., \& Herring, F.G. (2002). General Chemistry: Principles and Modern Applications. $8^{\text {th }}$ ed. San Francisco: Benjamin Cummings, Pearson Education.

Robertson, A.D., \& Shaffer, P.S. (2013). University student and K-12 teacher reasoning about the basic tenets of kinetic-molecular theory, Part I: Volume of an ideal gas. American Journal of Physics, 81, 303.

Sahin, C., \& Cepni, S. (2012). Effectiveness of instruction based on the $5 \mathrm{E}$ teaching model on students' conceptual understanding about gas pressure. Necatibey Faculty of Education Electronic Journal of Science and Mathematics Education, 6(1), 220-264.

Seda Cetin, P. (2009). Effects of Conceptual Change Oriented Instruction on Understanding of Gases Concepts. Ankara, Turkey: Unpublished Doctoral Dissertation, the Graduate School of Natural and Applied Sciences of Middle East Technical University.

Southerland, S.A., Abrams, E., Cummins, C.L., \& Anzelmo, J. (2001). Understanding students' explanations of biological phenomena: Conceptual frameworks or P-prims? Science Education, 85, 328-348.

Stavy, R. (1991). Children's ideas about matter. School Science and
Mathematics, 91(6), 240-244.

Suits, J.P. (2000). Conceptual Change and Chemistry Achievement: A Two and Dimensional Model. New Orleans, LA: Paper Presented at the Annual Meeting of the American Educational Research Association.

Taber, K. (2002a). Chemical Misconceptions-Prevention, Diagnosis and Cure. Volume I: Theoretical Background. United Kingdom: Royal Society of Chemistry.

Taber, K.S., (2002b). Alternative Conceptions in Chemistry: Prevention, Diagnosis and Cure? United Kingdom: The Royal Society of Chemistry.

Westbrook, S.L., \& Marek, E.A. (1992). A cross-age study of student understanding of the concept of homeostasis. Journal of Research Science Teacher, 29, 51-61.

Yalcinkaya, E. (2010). Effect of Case Based Learning on $10^{\text {th }}$ Grade Students' Understanding of Gas Concepts, their Attitude and Motivation. Ankara, Turkey: PhD Thesis Submitted to The Graduate School of Natural and Applied Sciences of Middle East Technical University.

Yavuz, S., \& Celik, G. (2014). The effect of predict-observe-explain (POE) technique on the misconceptions of prospective elementary teachers about the gases. Karaelmas Journal of Educational Sciences, 1, 1-20. 